\title{
Effect of Reheat Capacity in the Performance of a Model Heat Pump Dryer
}

\author{
V.Antony Aroul Raj, J. Kamalesh, R. Pradeep Kumar, J. Raghavendran, A. K. Babu, \\ G.Kumaresan
}

\begin{abstract}
Drying of vegetables is a developing million-dollar food industry. It plays an important role in vegetable chipmaking industry. It is very important to maintain the shape of the sliced vegetable during drying in the chips making process. In this research, the drying and deformation characteristics of eggplant slices, which are commonly used as edible chips, are carried out in a special type of equipment, in a transparent weighing chamber, so that the product can be visualized for deformity and shrinkage during the course of drying. In this work, the drying characteristics of slices have been studied in detail for different heat conditions and are compared.
\end{abstract}

Keywords- Moisture removal, Drying, Eggplant, Dehumidification.

\section{INTRODUCTION}

Drying or dehydration is one of the common processes used for improvising the shelf life and stability of fruits and vegetables. The process of drying the vegetables and fruits is to remove the water content present in it, which inhibits the microbial growth and reduces microbiological activity in it, thus minimizing the vegetables physical and chemical changes during its storage (Mayor and Sereno, 2004). The bound moisture that is trapped within the microstructure of the solid must be completely removed for achieving the maximum benefits from the drying process. The drying process has a direct impact on the shape, drying characteristics, drying quality and energy consumption of the dried materials. The drying shrinkage-deformation phenomenon of fresh fruits and vegetables is an important factor which affects the drying quality and efficiency. Shrinkage occurs simultaneously with moisture diffusion during drying and may, consequently, affect the moisture removal. The formation mechanism of drying shrinkagedeformation can be attributed to the heat-mass transfer during the drying process.

The drying characteristics for a batch of vegetable can be carried out by considering the characteristics obtained by experimenting a thin-layer of the vegetable.A thin-layer material is fully exposed to an airstream during drying. It is assumed that the temperature distribution of a thin-layer

Revised Manuscript Received on 14 September, 2019.

Antony Aroul Raj, Easwari Engineering College, Bharathi Salai, Chennai-600089, Tamilnadu, India.

J. Kamalesh, Easwari Engineering College, Bharathi Salai, Chennai600089, Tamilnadu, India.

R. Pradeep Kumar, Easwari Engineering College, Bharathi Salai, Chennai-600089, Tamilnadu, India.

J. Raghavendran, Easwari Engineering College, Bharathi Salai, Chennai-600089, Tamilnadu, India.

A. K. Babu, Easwari Engineering College, Bharathi Salai, Chennai600089, Tamilnadu, India.

G.Kumaresan, Institute for Energy Studies, Anna University, Sardar Patel Road, Chennai-600025, Tamilnadu, India. material is uniform. This is due to the thin-layer characteristics, thus making use of lumped parameter models suitable for thin-layer drying. The thin-layer drying is considered because of the non-isotropic and nonhomogenous nature of vegetables, along with the irregular shape and structural changes during drying (Sarasavadia et al., 1999).

The thin-layer drying method is incorporated in many experiments. Recent studies are being done on drying with different vegetables. For example, Alireza et al., 2009 have done experiments on shrinkage of Potato slice during drying. Many other types of research are carried out where the experiment is monitored with the help of Machine vision systems for the shrinkage and deformation in the vegetable slices. Eggplant is chosen as the vegetable for this research as it is most commonly used in cooking and also has lesser shelf-life for freshness. The experimental thin-layer drying of eggplant is done by Ertekin et al., 2004, for different thickness of the sample slices.

This experiment deals with identifying the shrinkage and deformation characteristics of the eggplant, when moisture defecit air is passed over the samples, observing the weight loss occurring with respect to time at specific intervals for over a range of five different heat input conditions.

\section{DRYING PARAMETERS}

\section{Initial moisture content}

The amount of water content present in the vegetable initially is known as the Initial Moisture Content. It is calculated using the following formula

Initial Moisture Content $(\%)=$

100

$$
\frac{\text { Dead weight }}{\text { Initial weight }} \times 100
$$

\section{Amount of dry material in the sample}

Dry material refers to the amount of vegetable material remaining after the removal of moisture content from it.

Amount of dry material in sample (grams)

$=$

100

$100+$ Initial moisture content $(\%)$ $\times$ Initial weight $(g)$

\section{Amount of moisture removed in the sample}

The moisture present in the sample is calculated for the purpose of determining the moisture ratio. The following 
formula gives the total moisture content present in the sample being dried.

Amount of moisture removed in the sample (grams)

$=$ Intial weight - Amount of dry material in the sample

\section{METHODS}

\section{Sample preparation}

The fresh Indian eggplant was brought from a local market at Chennai, Tamilnadu, India, sorted and washed. Samples to be dried are sliced into very thin layers, for 3 $\mathrm{mm}$ of uniform thickness.

\section{Drying experiment}

Drying experiment was carried out by placing thin-layer sliced eggplant samples in a drying chamber, which was supplied with moisture deficient air from one side. A dehumidifier is used to remove the moisture content present in the air and pumps the air into the drying chamber. Filament bulbs of 40 watts were used to provide heat to the air. The change in characteristics was observed by increasing the number of bulb source, which is parallelly connected to the power source, as shown in Fig.1 and 2.

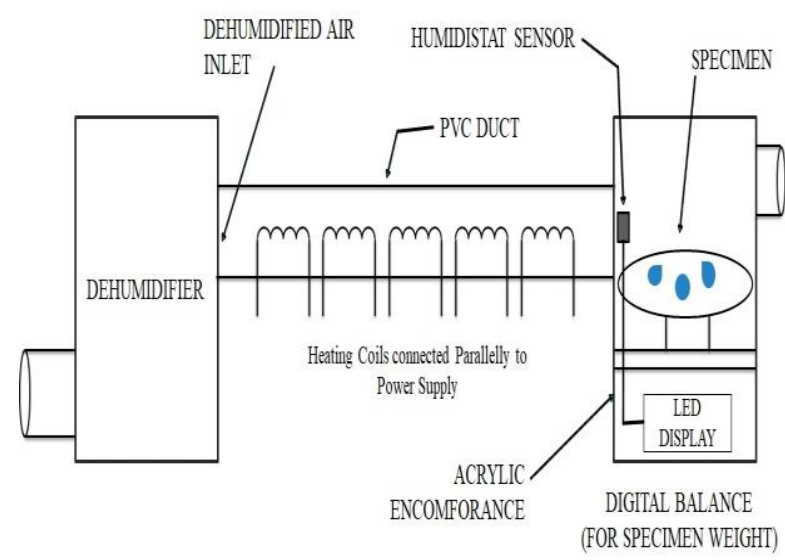

Fig.1: Layout of experimental setup

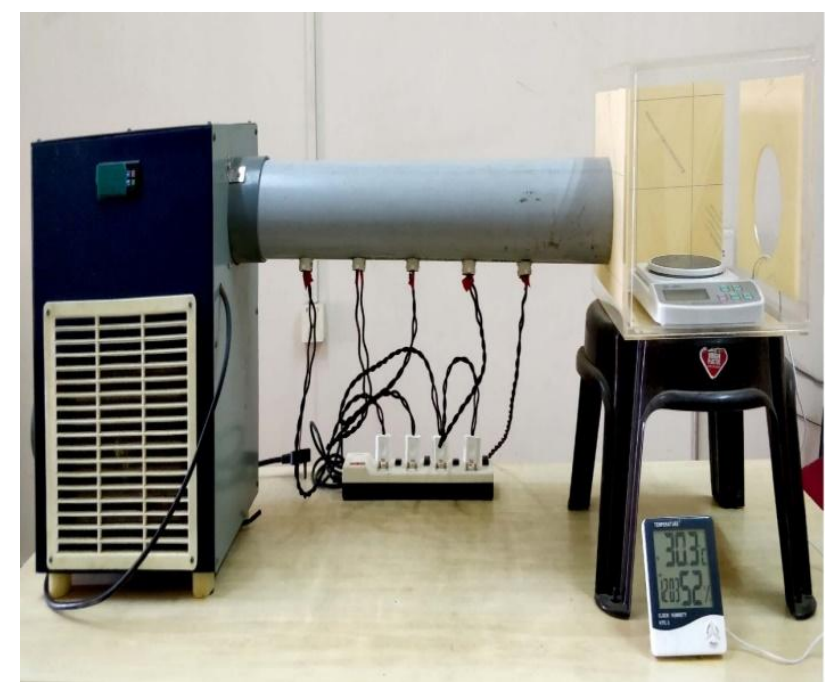

Fig 2: Photograph of experimental setup

The eggplant samples were placed on a tray kept on top of a precision balance, enclosed inside the drying chamber. This configuration allows the moisture from the sample to be removed from the upper surface. The moisture removed from the sample is carried away by air through the outlet of the chamber. The water removal is calculated by measuring the simultaneous changes occurring in the weight lost by the thin-layer of eggplant, for a specified period of time.

The same setup is repeated for a different heat input condition by increasing the number of active bulbs. During the course of drying, internal stresses occur within the samples. This is due to the removal of moisture from the inner side of the eggplant sample due to diffusion. This is evident once the samples undergo tremendous shrinkage, reducing the width and thickness of the sample. The temperature, humidity and air velocity are also noted at each configuration. The air velocity at the input was maintained at $3 \mathrm{~m} / \mathrm{s}$. It was measured with the help of an Anemometer. The experiment was stopped when there was a considerate amount of shrinkage in the sample visible and there was no significant change in weight of the resultant sample for a long period of time. This indicates that the moisture from the eggplant samples was removed to critical equilibrium moisture level.

The initial weight of the vegetable is noted from the digital weigh scale readings. The dead weight (dry matter) of the vegetable which is the weight of the material after the complete removal of water content present in it, was also found out.

\section{RESULTS AND DISCUSSION}

The deformation of the eggplant samples was observed with the rise of the circumference of chips away from the flat surface, which probably started after 50 minutes of the drying period. The shrinkage was visually identified when the area of samples started to reduce compared to the initial and it was observed after 75 to 100 minutes of the drying period. Constant weight or equilibrium weight was witnessed when there was no fluctuation in weight reduction for a prolonged time span of 30 minutes, which was most evident around 225 minutes of the drying period.

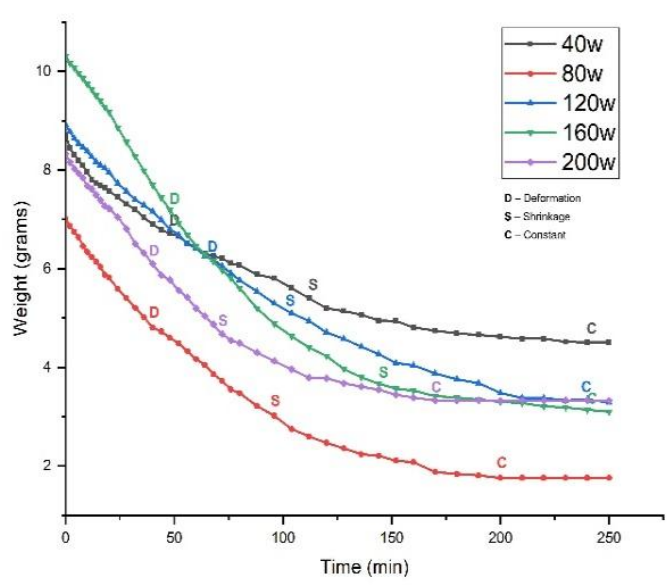

Fig.3: Drying rate with respect to time

When the heat source is increased, the drying time decreases. From the graphs, it is clearly understood that during the initial stages of drying, a faster rate of water removal occurs and it decreases with the increase in time. 
Drying rate spontaneously decreases with an increase in drying time. Higher heat sources had a drastic drying rate increase and fluctuation in the initial drying period of about 80 minutes. Moisture ratio reduces with increase in time, in which the heat source $160 \mathrm{~W}$ and $200 \mathrm{~W}$ had more initial moisture removal compared to other heat sources.

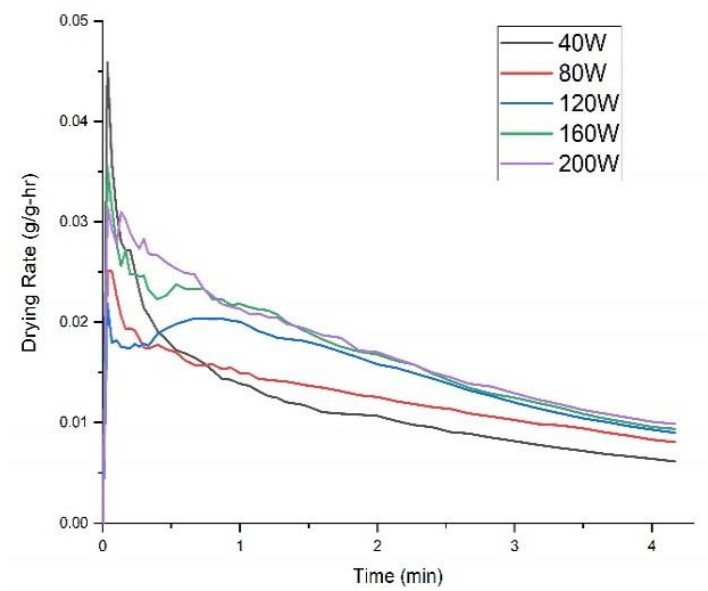

Fig.4: Drying rate with respect to time

There are two regions which can be identified from the graph (Fig.5). First, there is a rapid drop region and then the removal rate gradually slows. This graph clearly supports the fact that during the initial stages the moisture is removed quickly due to the accumulation of the water content at the surface of the eggplant slices. As time progresses, the drying rate reduces as the water content in the specimen reduces. Moreover, much work has to be done in removing the moisture that is trapped inside the porous specimen than removing the moisture present at the surface. Hence, the drying rate gradually slows down with an increase in time.

There is no warm-up period observed because of the thinlayer drying of the eggplant samples. Moreover, the rate of weight reduction is higher during the initial stages because of the removal of moisture present at the surface of the samples. It slows down with the progression of time due to the removal of water from the interior of the vegetable.

It can be inferred that the lesser specimen thickness helps more moisture to escape through additional exposed surface even at lower drying temperature. Therefore, the moisture removal rate depends upon the surface area and thickness of the specimen.

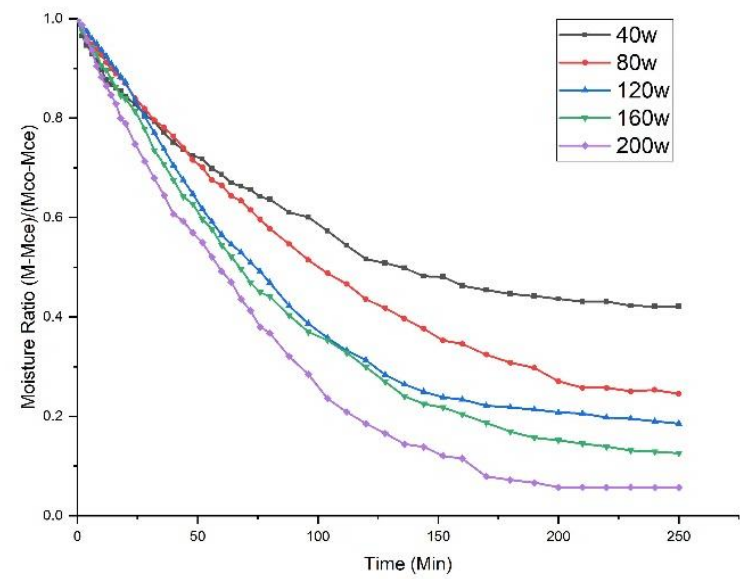

Fig.5: Moisture ratio with respect to time
The main objective of this study is to find out the drying characteristics of the Eggplant in order to optimize the conditions that control the drying rate for the longevity of the dried samples. This can only be determined by taking into account the moisture removal rate (Fig.5) from the eggplant. Shape Deformation also plays a major role, as drying the vegetable may cause the shape to vary drastically. Three distinct points D,S,C are identified in the experimental result as given in the figure 3 . D represents the zone of deformation, $S$ represents the zone of shrinkage of the product and $\mathrm{C}$ represents the constant moisture content. These are the points of distinct slope change of the drying curve. By monitoring the rate of drying it is possible to identify these zones stop the drying before the product deforms and shrinks. Deformation and shrinkage will result in the reduced product quality particularly in the chip making industry.

\section{CONCLUSION}

In this research, the calculation of the drying process in different heat input conditions in a heat pump drier and the moisture removal were represented graphically. In this work a method for predicting the deformation and shrinkage much before the actual process and stopping the drying process for maintain the shape and quality has been done. The deformation and shrinkage can clearly identified from the change in the slope of drying curve.

\section{REFERENCES}

1. Amalendu Chakraverthy \& Paul Singh, R. (2014). Postharvest Technology and Food Process Engineering. Taylor \& Francis Group: CRC Press.

2. Antonio Brasiello, Ginseppina Adiletta, Paola Russo, Silvestro Crescitelli \& Donatella Albanese. (2013). Mathematical modeling of eggplant drying: Shrinkage effect. Journal of Food Engineering, 114, 99-105.

3. Alireza Yadollahinia \& Mehdi Jahangiri. (2009). Shrinkage of Potato slice during drying. Journal of Food Engineering, 94, 52-58.

4. Beneseddik, A., Azzi, A., Zidoune, A. \& Allaf. K. (2018). Mathematical empirical models of thin-layer airflow drying kinetics of pumpkin slice. Engineering in Agriculture, Environment and Food, 11, 230-231.

5. Ertekin, C. \& Yaldiz, O. (2004). Drying of Eggplant and selection of a suitable thin-layer drying model. Journal of Food Engineering, 63, 349-359.

6. Hasan, A.A.M., Bala, B.K. \& Rowshon, M.K. (2014) Thin-layer drying of Hybrid rice seed. Engineering in Agriculture, Environment and Food, 7, 169-175.

7. Jangam, S.V \& Mujumdar, A.S. (2010). Drying of Foods, Vegetables and Fruits. Vol.1. pp.1-30. Singapore: National University of Singapore.

8. Mayor, L. \& Sereno, A.M. (2004). Modeling shrinkage during convective drying of food

9. materials: A review. Journal of Food Engineering, 61, 373-386.

10. Petru-Marian Carlescu, Vlad Arsenoaia, Radu Rosca \& Joan Tenu. (2017). CFD simulation of heat and mass transfer during apricots drying. LWT-Food Science and Technology, 85, 479-486. 
11. Sarsavadia, P.N., Sawhney, R.L., Pangavhane, D.R. \& Singh, S.P. (1999). Drying behavior of brined onion slices. J. Food Eng., 40, 219-226.

12. Thorpe, G.R. (2008). The application of computational fluid dynamic codes to stimulate heat and moisture transfer in stored grains. Journal of Stored Products Research, 44, 21-31.

13. Yuejin Yuan, Libin Tan, Yingying Yuan \& Jixian dong. (2019). Numerical and Experimental study on drying shrinkage-deformation of apple slices during the process of heat-mass transfer. International Journal of Thermal Sciences, 136, 539-548 